\title{
Assessing the sustainability literacy of the Nigerian engineering community
}

\author{
Usman Akeel ${ }^{1}$, Sarah Bell and John E. Mitchell \\ University College London, United Kingdom
}

\begin{abstract}
Being the lifeblood of socioeconomic progress, engineering is implicated in the unprecedented challenge of sustainability. The global engineering community devised sustainable engineering as a conceptual departure from conventional engineering practices. However, the extent to which the sustainability worldview has permeated the Nigerian engineering community remains unanswered. This paper is an attempt to answer the question of how sustainability literate are the members of the Nigerian engineering community. The paper undertakes an assessment of the sustainability literacy of the community with the aid of a stakeholder survey and a devised sustainability literacy test. Three criteria that are used to gauge the stakeholders' sustainability literacy are awareness of the UN Decade of Education for Sustainable Development, score on the sustainability literacy test, and self-assessment of sustainability knowledge. Survey participants were recruited mainly from two federallyrun Nigerian higher education institutions, and engineering professional associations. The assessment reveals an unsatisfactory performance of the Nigerian engineering stakeholders on all three sustainability literacy criteria. The results show that the majority of the students $(81 \%)$, educators $(67 \%)$, and practitioners $(64 \%)$ were unaware of the UNDESD. The paper therefore highlights the need to improve the sustainability literacy of the Nigerian engineering community, possibly through a sustainability education intervention.
\end{abstract}

Keywords: Sustainability literacy, Assessment of sustainability knowledge, UNDESD, Sustainability literacy test, Sustainable engineering community

\section{Introduction}

Engineering is intricately connected with the complex problems of sustainability, owing to its role in delivering technologies and infrastructures to satisfy human needs and aspirations. Going forward into the future, engineering is largely required to transform into sustainable engineering guided by a sustainability worldview, which is poised to induce in individuals the cognitive orientation necessary to make sense of an increasingly complex and unpredictable world (Allenby, 2007). However, designed chiefly in a developed world context, the theory and practice of sustainable engineering has failed to gain much traction in the developing world. This has raised concerns about the level of sustainability knowledge in those regions (Etse and Ingley, 2016).

Partly to address these concerns, the UN created alongside the Decade of Education for Sustainable Development (UNDESD) the Mainstreaming Environment and Sustainability in African Universities Partnership (MESA). The MESA baseline study in 2004 indicated that a plethora of hurdles stood in the way of sustainability literacy in Africa (UNEP-MESA, 2009). The study concluded that sustainability education "was slow to evolve in Africa" owing to the continent's other countless post-colonial challenges (Thakran, 2004). Corroboratively, the UNDESD Final Report indicated that "sustainable development is only an emerging interest amongst African higher education institutions" (UNESCO, 2014, p.95).

Nigeria is one of the African countries referenced in the MESA study and the UNDESD Final Report. Members of the Nigerian engineering community are typically trained in various higher education institutions in the country. Although in 2009, Nigeria ratified the Abuja Declaration

\footnotetext{
${ }^{1}$ usman.akeel.09@ucl.ac.uk
} 
which sought to mainstream sustainability into African higher education institutions, the country has no explicit sustainability education framework. Nigerian engineering graduates and students may be hard-pressed to proficiently practice sustainable engineering, which is crucial to addressing regional and global sustainability. To partake in sustainable engineering necessarily requires a degree of sustainability literacy. However, how sustainability literate members of the Nigerian engineering community are remains unanswered. Answering the question will not only provide a baseline for sustainability education interventions in Nigerian engineering curriculum, but also serve as a gauge of the efficacy of international sustainability efforts including the UNDESD.

This paper assesses the sustainability literacy of the Nigerian engineering community. The purpose of the paper is to determine the current level of sustainability knowledge amongst the engineering community in Nigeria. The study involves a survey administered to three clusters of the Nigerian engineering community - students, educators, and practitioners. Three criteria against which the sustainability literacy of the community is measured include the level of UNDESD awareness, performance on a sustainability literacy test, and self-assessment of sustainability knowledge. The paper proceeds with a brief overview of sustainability literacy and engineering in Nigeria. Thereafter, the methods of the study are described before the results of the assessment are presented. A synthesis of the results to approximate the sustainability literacy level of the Nigerian engineering community is undertaken. The paper concludes that sustainability literacy is low in Nigeria, across all cohorts studied in each of the three criteria assessed.

\subsection{Engineering in Nigeria}

Engineering in Nigeria evolved as a necessary outcome of colonialism. Engineering activities were undertaken to facilitate and advance the goals of colonial government centred around governing Nigerian territories to expand commerce and promote progress and civilisation (Falola and Heaton, 2008). Accordingly, road and railroad construction, provision of water supply, waste management, mining, dredging, housing, electrical and mechanical works featured prominently amongst recurrent engineering projects in colonial Nigeria. The establishment of Public Works Department (PWD) by the southern Lagos government in 1896 institutionalised engineering practice in the colony (Ojiako, 1986). PWD Lagos, which comprised three units, namely civil, mechanical and electrical, was tasked with addressing engineering problems in the colonial region. Similar PWD outfits were established by the other regional governments of Northern and Eastern Nigeria after independence in 1960.

The engineering legacy bequeathed to Nigeria by the British continued without much change. Indigenisation efforts progressed very slowly as British and other foreign engineers continued to direct various engineering works across the country. Over the years, Nigeria began to take full ownership of engineering practice in the country. Professional associations emerged including the Nigerian Society of Engineers, the Council for the Regulation of Engineering in Nigeria, and the Nigerian Academy of Engineering. These bodies acted as consultants to successive Nigerian governments and to the academia broadening the purview of engineering knowledge and ensuring professionalism. Presently, engineering practice in Nigeria occurs within the structure of governmental regulation and professional associations' guidance. Only registered engineers are permitted by law to practice engineering in Nigeria. Presently, there are some 30 engineering fields approved and practised in Nigeria (COREN, 2016).

The pathway to a professional engineering career in Nigeria begins with a university degree. Initial move towards educating Nigerians in the technical field was in the form of two technical colleges of Yaba Technical Institute (now Yaba College Technology) and Technical Institute 
Kaduna (now Kaduna Polytechnic) established in 1948 and 1958 respectively. However, engineering education in the modern sense debuted in Nigeria in 1961 when College of Engineering, (now Faculty of Engineering) was created at the newly established University of Nigeria Nsukka in Enugu. Other engineering faculties were subsequently established in 1962 at University College Ibadan, now University of Ibadan, and Ahmadu Bello University Zaria. These efforts to educate indigenous engineers in Nigeria proved successful. An engineering degree in Nigeria is now acquired over a 5-year period in several higher education institutions, which numbered 143 in 2016 comprising 40 federal universities, 42 state universities and 61 private universities (NUC, 2016). General physical and chemical science subjects accompanied by one or two social science subjects including Use of English and the Engineer in Society are taught to first- and second-year engineering students. Students are progressively exposed to the core of their chosen disciplines over the next three years. An industrial work experience scheme is sandwiched in the engineering programme. In the final year of their programme, engineering students undertake a research project either individually under the supervision of an academic.

\subsection{Sustainability education in Nigeria}

Sustainability education arose in Nigeria in the form of environmental education. This has remained the dominant conception of sustainability education in the country. The mention of education in several sustainable development-related documents such as Nigeria's Agenda 21, National Educational Policy and Nigeria Vision 20:2020 ${ }^{2}$ is either in reference to "education for all" or to an environmental education. Given such impression of sustainability education, the Nigerian educational system has responded with chiefly environment-related courses and instructions. Lessons on such environmental subjects as natural resources, public health economics, environmental sanitation, and pollution amongst several others permeate primary educational curricula. In the secondary schools, students are introduced to more advanced environmental issues including waste and land pollution, climate change, ecology and water pollution.

The permeation of environmental education into Nigerian HEIs engendered several academic programmes with Environmental Engineering, Environmental Management, Environmental Technology and Environmental Resources Management covered within engineering education. Sixteen Nigerian universities currently offer these courses (JAMB, 2017). Sustainability education in the form of education for sustainable development or engineering education for sustainable development has not gained much recognition in the Nigerian educational system. Despite ratifying the Abuja Declaration which sought mainstreaming sustainability education into African universities (AAU, 2009), Nigeria has no explicit sustainable higher education framework. There is apparently no Nigerian HEI that currently offers a strictly sustainability degree $^{3}$. The absence of a purposefully designed sustainability programme in the Nigerian HEIs has also been suggested by MESA study in 2004 and the UNDESD Final Report in 2014.

The prospect of an accelerated uptake of context-relevant sustainability education in Nigeria has equally not been realised even with the existence of the UN-established Regional Centres of Expertise (RCE) on ESD. Developed following the start of UNDESD in 2005, the concept of RCE features formal, non-formal, and informal educational systems in the promotion of sustainability education. In Nigeria, RCEs are located in Kano, Minna, Port-Harcourt and Lagos. Although appreciable progress has been made in terms of the informal and non-formal components of ESD by the RCEs, the formal element is inadequately attended to. Contributing

\footnotetext{
${ }^{2}$ An economic transformation blueprint prepared in 2009 by the National Planning Commission articulating development strategies to position Nigeria among the 20 largest economies in the world by 2020 .

${ }^{3}$ This is based on the JAMB Brochure which contains all the courses offered in Nigerian HEIs.
} 
to this undesirability is the failure of the RCEs to successfully network with Nigerian HEIs thereby fragmenting the sustainability education initiative. Renewed networking efforts are required to mainstream sustainability education into the Nigerian HEIs. A means of achieving this is through the education and environment ministries, the Council for the Regulation of Engineering in Nigeria (COREN) and the National Universities Commission (NUC).

\subsection{Sustainability literacy}

Sustainability literacy has been defined variously in the literature. A number of scholars delineate sustainability literacy in terms of "skills, attitudes, competences, dispositions and values" necessary for delivering a sustainable world (Stibbe, 2010, p.15). The global non-profit consultancy, Forum for the Future, explains that a sustainability literate person should "understand the need for change to a sustainable way of doing things, individually and collectively". Furthermore, such a person should "have sufficient knowledge and skills to decide and act in a way that favours sustainable development". Further, sustainability literacy should enable one "to recognise and reward other people's decisions and actions that favour sustainable development" (Parkin et al., 2004, p.9). Another characterization of sustainability literacy describes it as "knowledge, skills and understanding required to fashion a more sustainable future" (Vare and Blewitt, 2010). Definitions of sustainability literacy emphasise both knowledge and skills. However, the most common instrument employed to test sustainability knowledge is in the form of a quiz and focus on knowledge.

Most sustainability literacy tests (SLT) feature a set of multiple choice questions as typified in the Assessment of Sustainability Knowledge (ASK) developed by the Ohio State University in conjunction with the University of Maryland (Zwickle et al., 2013). ASK contains 16 multiple choice questions about wide-ranging global sustainability issues as well as matters of contextual relevance to the United States. An important distinction of the ASK instrument is its focus on factual knowledge as opposed to beliefs and values. The questions on ASK are expert-derived involving contributions of academics from various disciplines. For its several utilisations, the instrument was deployed online aided by the SurveyMonkey software package (Zwickle et al., 2014). Some constraints of the ASK tool are related to the conventional limitations of multiple choice questions and the inapplicability of the tool in other national contexts. Also, the ASK instrument assesses foundational knowledge and not necessarily literacy at the levels of analysis, synthesis, and evaluation.

An effort to evaluate sustainability knowledge worldwide yielded the first international sustainability literacy test dubbed The Sulitest (Carteron and Decamps, 2017). The Sulitest is an online multiple choice questionnaire divided into three modules: core, specialised (and customised), and surveys. The development of the Sulitest benefited from inputs of reputable sources in the sustainability research community. The tool is supported by the UN and has so far been used by at least 612 educational institutions from around the world (Sulitest, 2017). To partake in the test, an institution must register on the Sulitest website and appoint a representative known as the Focal Point. An examiner is also chosen by the applying institution to set the customised questions. Students can only take the test after accessing a code generated by their institution's examiner. Some limitations of Sulitest commonly cited are questionnaire length, overrepresentation of some countries, and inherent constraints of multiple choice questions. 


\subsection{Sustainability literacy research}

Several studies have been undertaken to ascertain the sustainability literacy of the engineering community around the world. A research which sought to answer the question of how much engineering students know about sustainable development was conducted in 2005 by Azapagic et al (2005). The study proceeded as a world-wide survey of engineering students inquiring about their level of knowledge and understanding of environmental and sustainability issues. The outcome of the study was that engineering students largely exhibited a low level of sustainability knowledge. The research also suggested that much more effort was needed to educate engineering students on sustainable development. An interesting insight from the study was that, on average, the students were comparatively more aware of environmental issues than they were of social and economic sustainability. Interestingly, the students indicated strong personal relevance and professional importance of sustainability issues. However, the study was limited to students mainly from European and American universities. Not a single African university was involved in the study. Moreover, there was an overrepresentation of chemical engineering students, who constituted $75 \%$ of the respondents. Thus, conclusions from the study, even though invaluable, must be done cautiously.

Relatedly, Zwickle et al (2014) assessed the sustainability literacy of the undergraduate students at The Ohio State University. Over 1,000 students participated in the web-based and campus-wide survey, which featured 16 multiple-choice questions covering the three sustainability domains - economy, environment, and society. Being campus-wide, the test involved students from several academic disciplines including the engineering sciences, although this was not explicitly categorised. One of the objectives of the test, according to the researchers, was to quantify the students' knowledge of sustainability, both as a broad and an abstract concept. The featured questions encompassed the fundamental ideas of sustainability as represented in each of the three sustainability pillars. Since the test was administered in the US, some of the questions were necessarily US-specific. The test results were reported as mean percentages of student responses to the multiple-choice questions.

The study discovered that an average of $69 \%$ of the students answered the questions correctly. Across the three sustainability domains, a significant majority $(>70 \%)$ of the students answered the environmental and economic questions correctly. Only about three-fifths of the students responded correctly to the social questions. An interesting question that enquired about the function of the ozone layer returned over $90 \%$ correct responses. Contrastingly, a question that sought the most commonly used definition of economic sustainability was answered correctly by just $46 \%$ of the students. Across class rank, the results showed that the performance of freshmen on the test was lower than that of the sophomores and juniors. A surprising finding reported by Zwickle et al was that aeronautical engineering students perfomed better than the rest of the students. Although the study represents an important contribution to sustainability education, it could have extended the literacy test to the educators. This would have provided an insight into how the educators compared with the students.

\section{Methods}

\subsection{Sample size}

The survey population in this research was the Nigerian engineering community. Although it was challenging to ascertain the population of the Nigerian engineering community, an estimated figure of 100,000 was assumed in the present study. This figure was arrived at based on the number of COREN registered engineers (estimated at 30,000) and on the number of 
engineering students and educators estimated from the guide provided by the COREN (estimated at 65,000 and 5,000 respectively) (COREN, 2016). Using a 95\% confidence level and a 5\% margin of error, a sample size of 383 was calculated for the Nigerian engineering community. However, the sample size that was eventually achieved in the study was $\mathbf{n}=\mathbf{4 4 2}$. Of the 442 respondents, 232 were engineering students $(n=232), 84$ participants were educators $(n=84)$ and 126 were practitioners $(n=126)$. The study intended to reflect the diversity within the Nigerian engineering community by involving as many students, educators, and practitioners as possible from several engineering disciplines. Consequently, over 20 Nigerian universities were invited to participate in the study out of which five responded positively. Of these, only two provided access to their engineering students and educators. Therefore, the willingness of the universities to participate in the research eventually informed the choice of the participants in the study. Notwithstanding this challenge, the sample is representative of the engineering community given the largely common experience of engineering amongst the three groups as they study, teach and practice the discipline.

The engineering students and educators were recruited chiefly from two federally-run Nigerian HEIs, targeting postgraduate as well as fourth- and final-year undergraduate students. The sample comprised 10 doctoral, 74 master's and 148 undergraduate students, with 40 female and 192 male students. Engineering educators were sampled from the same higher education institutions as the students cutting across various engineering disciplines. The educator sample consisted of 10 female and 74 male respondents with 25 bachelor's degree, 40 master's degree, and 19 doctorate degree holders. The engineering practitioners were recruited from the Nigerian Society of Engineers and the Council for the Regulation of Engineering in Nigeria. The composition of the practitioner sample was 81 public servants with 42 and 3 professionals in the private and multinational employment respectively. Furthermore, the practitioner sample comprised 121 male and 5 female participants. The educational level of the sampled practitioners featured 88 bachelor's degree, 36 master's degree and 2 doctorate degree holders with differing lengths of professional experience (46 people in the range of 0-5 years, 51 had between 6-10 years of professional experience, 20 had worked for 11-15 years, and 3 had over 30 years' experience).

\subsection{Data collection}

Closed-ended survey questions and a SLT were used to examine the sustainability knowledge of the Nigerian engineering community. The survey featured a yes-no question on whether respondents were aware of the UNDESD. The SLT was designed based on several sustainability literacy assessment tools in the literature. Instruments such as ASK and Sulitest were helpful in the development of the SLT. Full-scale adoption of the ASK was not possible as it did not only feature US-specific questions, but also had the demerit of high response burden in relation to the present study. Similarly, the Sulitest was considered unsuitable for the reasons of bureaucracy and inadequate alignment with the purposes of the present research. As established in the review of the Sulitest (Carteron and Decamps, 2017), registration for the test involves a somewhat complicated administrative procedure. Not only would it be difficult to convince the Nigerian higher educational institutions and engineering professional associations to register for the online test, but it was not possible in the timeframe of the current research project. Furthermore, the Sulitest is more appropriate for testing higher levels of sustainability literacy as opposed to knowledge of sustainability basics targeted in the present study. Since none of the extant tools could be used unaltered for the purposes of the study, a bespoke SLT was designed. 
An important modification in the SLT was the use of true/false/do not know format rather than the multiple choice questions of ASK and Sulitest. This questioning style was informed by the need to optimise test duration as well as maintain test integrity. Additionally, it was important to reduce random guessing by encouraging respondents to admit a lack of knowledge where appropriate. Another alteration in the SLT was the feature of context-relevant questions focusing on Nigeria. Contextual relevance had been repeatedly recommended in the design of sustainability knowledge assessment tools in the literature (Sulitest, 2017). Thus, the 15 questions featured on the SLT covered environmental, economic, social and crosscutting domains of sustainability with an element of contextual issues. However, these domains were not visibly delineated on the SLT as the questions were mixed to avoid a modular test design. The questions were generally framed to test foundational knowledge as an aspect of sustainability literacy. The economic questions featured on the test were Q5, Q8 and Q10, whilst Q1, Q2 and Q5 represented the environmental questions. Q6, Q7 and Q9 addressed the social questions with Q3, Q4 and Q11 focusing on the crosscutting issues. Sustainability literacy levels such as application, analysis, evaluation, skills, and disposition were not tested since the Nigerian engineering community had not been previously studied for sustainability knowledge (Akeel et al., 2017). Hence, basic sustainability concepts were the topics of interest in the SLT. Both global and country-specific sustainability issues appeared in the four sustainability domains. A self-assessment question was appended to the SLT to gauge the overall perception of the respondents on their knowledge of sustainability based on the test. A pretesting of the instrument informed the final version of the research tool (Appendix A).

Paper-based and web-based means of survey administration were used in the present research. The paper-based survey involved physical distribution of the instrument to the respondents. The online survey, which was developed with the aid of a web-based tool, Opinio, was accessed via a survey link. The survey length for both survey types was 15 minutes. Each survey was prefaced with an overview highlighting the purpose of the study and issues of confidentiality and voluntariness of participation. However, before the administration of the surveys, the relevant organisations, namely the Council for the Regulation of Engineering in Nigeria, the Nigerian Society of Engineers, and the two HEIs were formally invited to participate in the research. An administrator was subsequently appointed by each organisation to coordinate the distribution of the surveys. Both the web-based and the paper-based surveys were routed through the representative of the organisations. The survey was administered (distributed and retrieved) over a period of three months (May - Aug 17). Follow up messages were sent fortnightly by the representatives to the respondents reminding and encouraging them to participate in the survey.

\subsection{Data assessment}

The three criteria used to assess the sustainability knowledge of the sampled Nigerian engineering community were level of awareness of UNDESD, performance on SLT, and selfassessment of sustainability knowledge. The level of awareness of UNDESD was analysed statistically as already explained above. It was essentially a closed-ended question demanding a yes or no response to whether participants were aware of the UNDESD. The frequency and percentage of each response classification were obtained. SLT was graded based on a ternary scoring format of correct, incorrect and do not know answers. Consequently, the fifteen test questions were each scored as correct, incorrect or do not know. The percentage of respondents who opted for each answer category was determined and the overall averages calculated.

Respondents to the SLT were also assessed based on the four domains of economic, environmental, social and crosscutting sustainability. This was intended to determine the 
performance of the community by sustainability topics. The average scores of the respondents on each of the four sustainability domains were calculated and expressed as percentages. This aided a comparison of performances on the sustainability topics. For the self-assessment of sustainability knowledge, statistical analysis was undertaken. However, the 5-point Likert scale of the self-assessment question (very poor, poor, average, good, very good) was reduced to low (very poor-average) and high (good-very good). This facilitated the delineation of selfassessed sustainability knowledge as either low or high, which did not only simplify the analysis but also provided a basis for comparison. Results of the three assessment criteria were synthesised to articulate the level of sustainability knowledge of the Nigerian engineering community.

\section{Results}

\subsection{Awareness of UN Decade of Education for Sustainable Development}

Table 1 presents the results of the UNDESD awareness query. The results revealed that a vast majority $(81 \%)$ of the students were not aware of the UN Decade, and only one-third of the educators $(33.3 \%)$ claimed knowledge of the UNDESD. Whilst a considerable number of the practitioners (36\%) said they knew about the UN Decade, the majority (64\%) was ignorant of it. Disaggregating the data by institution $(p=0.746)$, discipline $p=0.298)$ and educational level $(p=0.719)$ revealed no statistically significant differences. Thus, engineering students, engineering educators and engineering practitioners in Nigeria were generally unaware of the UNDESD.

Table 1. Stakeholder awareness of UNDESD

\begin{tabular}{|c|c|c|}
\hline $\begin{array}{l}\text { Survey prompt: Are you aware of the UN Decade of Education for Sustainable } \\
\text { Development? }\end{array}$ & Frequency & Percent \\
\hline \multicolumn{3}{|l|}{ Students $(n=232)$} \\
\hline Yes & 44 & 19.0 \\
\hline No & 188 & 81.0 \\
\hline Total & 232 & 100.0 \\
\hline \multicolumn{3}{|l|}{ Educators $(n=84)$} \\
\hline Yes & 28 & 33.3 \\
\hline No & 56 & 66.7 \\
\hline Total & 84 & 100.0 \\
\hline \multicolumn{3}{|l|}{ Practitioners $(n=126)$} \\
\hline Yes & 45 & 35.7 \\
\hline No & 81 & 64.3 \\
\hline Total & 126 & 100.0 \\
\hline
\end{tabular}

\subsection{Outcome of sustainability literacy test}

Table 2 displays the scores of the students, educators and practitioners on the SLT, which is expressed as a percentage of test-takers responding correctly and incorrectly to the 15 sustainability-related questions. There is also an option for the 'do not know' response. The correct answer to each question is placed next to the question in italics and parenthesised. Only Q8 was correctly answered by more than half $(51.7 \%)$ of the students. The student average percentage of incorrect answers was $32.1 \%$, whilst almost half of the students (48.8\%) admitted not knowing the answers. Furthermore, the results revealed that only one-fifth $(20.9 \%)$ of the educators performed well on the test. One-third (33.1\%) and almost half (46.0\%) of the educators answered the questions incorrectly and with a 'do not know' response respectively. Nonetheless, a large proportion (61.4\%) responded correctly to Q8. The most incorrectly 
answered question on the test was Q9 attracting only a small fraction of correct responses (3.6\%). Similarly, the practitioners recorded a significant amount of incorrect responses, with only one-quarter of the respondents answering the sustainability questions correctly. More than two-fifths $(40.5 \%)$ of the practitioners responded incorrectly to the questions, whilst one-third of them indicated not knowing the correct answers. Interestingly, the majority of the practitioners answered Q6 and Q8 correctly recording 52.1\% and 75.2\% correct responses respectively. Disaggregating the data by institution, engineering discipline, employment type, and academic qualification did not reveal any statistically significant differences $(p \leq 0.001)$. Hence, the performance of the Nigerian engineering students, educators and practitioners on the SLT was mostly poor.

Table 2. Outcome of sustainability literacy test

\begin{tabular}{|c|c|c|c|c|c|c|c|c|c|}
\hline Sustainability Literacy Test & & $\begin{array}{l}\text { tudent } \\
\text { n=232 }\end{array}$ & & & $\begin{array}{l}\text { lucato } \\
(n=84\end{array}$ & & Pract & oners ( & =126) \\
\hline \multirow[t]{2}{*}{ Question } & \multicolumn{3}{|c|}{$\%$ within group } & \multicolumn{3}{|c|}{$\%$ within group } & \multicolumn{3}{|c|}{$\%$ within group } \\
\hline & U⿺辶ِّ & 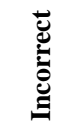 & 言 & 这 & 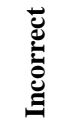 & 䓂言 & 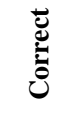 & 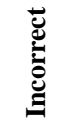 & 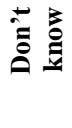 \\
\hline $\begin{array}{l}\text { Q1. Ozone layer protects us from acid rain and } \\
\text { temperature fluctuations. (False) }\end{array}$ & 10.0 & 66.1 & 23.9 & 10.8 & 72.3 & 16.9 & 17.1 & 76.9 & 6.0 \\
\hline $\begin{array}{l}\text { Q2. Carbon monoxide is one of the greenhouse gases } \\
\text { that cause global warming. (False) }\end{array}$ & 7.8 & 67.0 & 25.2 & 12.0 & 66.3 & 21.7 & 6.8 & 86.3 & 6.9 \\
\hline $\begin{array}{l}\text { Q3. The main focus of the Kyoto Protocol adopted in } \\
1997 \text { was nuclear waste. (False) }\end{array}$ & 7.4 & 16.1 & 76.5 & 13.3 & 21.7 & 65.1 & 11.1 & 17.1 & 71.8 \\
\hline $\begin{array}{l}\text { Q4. Agenda } 21 \text { is a global treaty signed by UN } \\
\text { member nations at the Stockholm Earth Summit in } \\
\text { 1992. (False) }\end{array}$ & 6.1 & 20.9 & 73.0 & 4.8 & 21.7 & 73.5 & 5.1 & 27.4 & 67.5 \\
\hline $\begin{array}{l}\text { Q5. Global population stood at } 1.6 \text { billion in } 1900 . \\
\text { (True) }\end{array}$ & 28.3 & 7.8 & 63.9 & 25.3 & 14.5 & 60.2 & 35.0 & 10.3 & 54.7 \\
\hline $\begin{array}{l}\text { Q6. Less than one million people in the world have no } \\
\text { access to clean drinking water. (False) }\end{array}$ & 28.3 & 26.5 & 45.2 & 49.4 & 13.3 & 37.3 & 52.1 & 21.4 & 26.5 \\
\hline $\begin{array}{l}\text { Q7. Engineers' role in sustainability suffices with } \\
\text { ensuring that their designs or systems do not harm the } \\
\text { environment. (False) }\end{array}$ & 10.5 & 63.8 & 25.8 & 4.8 & 73.5 & 21.7 & 12.8 & 82.9 & 4.3 \\
\hline $\begin{array}{l}\text { Q8. Long-term profitability is the most commonly } \\
\text { used definition of economic sustainability. (True) }\end{array}$ & 51.7 & 13.5 & 34.8 & 61.4 & 10.8 & 27.7 & 75.2 & 11.1 & 13.7 \\
\hline $\begin{array}{l}\text { Q9. The review of global poverty line to US } \$ 1.90 \\
\text { was spurred by worldwide sustainability activisms. } \\
\text { (False) }\end{array}$ & 5.2 & 19.6 & 75.2 & 3.6 & 18.1 & 78.3 & 7.7 & 25.6 & 66.7 \\
\hline $\begin{array}{l}\text { Q10. Economic development and environmental } \\
\text { protection are mutually exclusive. (False) }\end{array}$ & 27.4 & 36.5 & 36.1 & 31.3 & 39.8 & 28.9 & 38.5 & 46.2 & 15.3 \\
\hline $\begin{array}{l}\text { Q11. The sustainability pillars of environment, society } \\
\text { and economy are widely accepted to be in a } \\
\text { hierarchical, rather than equal, relationship. (False) }\end{array}$ & 14.8 & 39.3 & 45.9 & 7.2 & 43.4 & 49.4 & 10.3 & 57.2 & 32.5 \\
\hline $\begin{array}{l}\text { Q12. In the landmark Brundtland Report of 1987, the } \\
\text { terms sustainability and sustainable development are } \\
\text { used interchangeably. (True) }\end{array}$ & 22.6 & 6.1 & 71.3 & 21.7 & 1.2 & 77.1 & 25.9 & 6.0 & 68.1 \\
\hline $\begin{array}{l}\text { Q13. Nigeria failed to ratify the UN } 2030 \text { Agenda for } \\
\text { Sustainable Development in } 2015 \text { as presidential } \\
\text { elections held in the country at the time. (False) }\end{array}$ & 13.1 & 21.4 & 65.5 & 12.0 & 20.5 & 67.5 & 20.5 & 24.8 & 54.7 \\
\hline $\begin{array}{l}\text { Q14. Federal Environmental Protection Agency is the } \\
\text { primary agency that oversees environmental } \\
\text { regulation in Nigeria. (False) }\end{array}$ & 10.0 & 54.8 & 35.2 & 7.2 & 61.4 & 31.3 & 6.8 & 77.8 & 15.4 \\
\hline $\begin{array}{l}\text { Q15. Breeding of animals in zoos is the most } \\
\text { significant driver in the loss of species and ecosystems } \\
\text { around the world. (False) }\end{array}$ & 43.7 & 22.3 & 34.0 & 49.4 & 18.1 & 32.5 & 44.4 & 35.9 & 19.7 \\
\hline Average & 19.1 & 32.1 & 48.8 & 20.9 & 33.1 & 46.0 & 24.6 & 40.5 & 34.9 \\
\hline
\end{tabular}

\subsection{Performance by sustainability topics}

A sorting of the sustainability questions by topics was undertaken to check the performances of the test-takers across the domains of sustainability-economic, environmental, social and 
cross-cutting topic (Table 3). This rearrangement revealed that, for students, economic topics had, on average, the highest percentage $(35.8 \%)$ of correctly answered questions followed by the environmental questions $(20.5 \%)$. Social and cross-cutting topics recorded small fractions of correct responses (14.7\% and 9.4\% respectively). In addition, there were no statistically significant differences within the student population excepting slight variation based on educational level. Postgraduate students performed better than undergraduate students only on economic questions $(p \leq 0.001)$. However, no significant differences were observed in the remaining sustainability topics. Educators had a varied performance by sustainability topics. A good proportion $(39.3 \%)$ of the educators performed well on the economic questions, but did poorly $(8.4 \%)$ on the crosscutting topics.

More than a quarter of the educators (24.1\%) answered the environmental questions correctly. The social questions trailed behind the environmental topics with nearly one-fifth $(19.2 \%)$ of the lecturers responding with the correct answers. However, there were no statistically significant differences based on the educators' institution, discipline and academic qualification $(p \leq 0.001)$. The performance of practitioners on the sustainability literacy test varied according to sustainability themes. Nearly half of the practitioners (49.6\%) performed well on the economic questions. Almost a quarter of them (24.2\%) passed the social queries with a fraction of the professionals $(22.5 \%)$ answering the environmental questions correctly. However, on the crosscutting questions, a significant majority either provided incorrect answers (33.9\%) or admitted not knowing the correct answers (57.3\%). Disaggregating the data by discipline, employment, academic qualification and length of professional experience revealed slight statistically significant differences $(p \leq 0.001)$. Hence, the sustainability literacy of the students did not vary greatly by topics, but educators and practitioners differed somewhat slightly by themes.

Table 3. . Nigerian engineering community performance by sustainability topics

\begin{tabular}{|c|c|c|c|c|c|c|c|c|c|c|c|c|}
\hline \multirow{2}{*}{$\begin{array}{c}\text { Engineering } \\
\text { Community } \\
(\mathrm{n}=442 ; \\
p \leq \mathbf{0 . 0 0 1})\end{array}$} & \multicolumn{3}{|c|}{ Economic } & \multicolumn{3}{|c|}{ Social } & \multicolumn{3}{|c|}{ Environmental } & \multicolumn{3}{|c|}{ Crosscutting } \\
\hline & $\begin{array}{l}\stackrel{\circ}{ } \\
\overrightarrow{0} \\
\ddot{\Xi} \\
0\end{array}$ & $\begin{array}{l}\breve{0} \delta^{\circ} \\
\stackrel{\Xi}{0} \\
\stackrel{.}{\Xi}\end{array}$ & 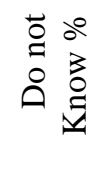 & $\begin{array}{l}0^{\circ} \\
\overline{0} \\
\stackrel{0}{0}\end{array}$ & 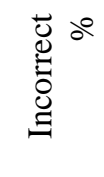 & 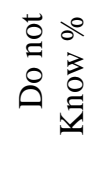 & $\begin{array}{l}\dot{0} \\
\overrightarrow{0} \\
\ddot{\Xi} \\
0\end{array}$ & 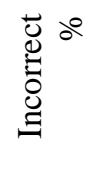 & 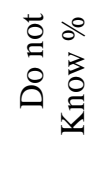 & $\begin{array}{l}0^{0} \\
\ddot{0} \\
\ddot{\Xi} \\
\ddot{0}\end{array}$ & 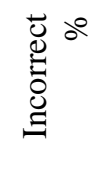 & 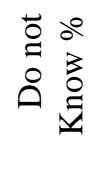 \\
\hline Students $(\mathrm{n}=\mathbf{2 3 2})$ & 35.8 & 9.3 & 44.9 & 14.7 & 36.6 & 48.7 & 20.5 & 51 & 27.7 & 9.4 & 25 & 65.1 \\
\hline Educators $(n=84)$ & 39.3 & 21.7 & 38.9 & 19.2 & 35.0 & 45.8 & 24.1 & 52.2 & 23.7 & 8.4 & 28.9 & 62.7 \\
\hline $\begin{array}{l}\text { Practitioners }(n= \\
\text { 126) }\end{array}$ & 49.6 & 22.5 & 27.9 & 24.2 & 43.3 & 32.5 & 22.8 & 66.4 & 10.8 & 8.8 & 33.9 & 57.3 \\
\hline Average & 41.6 & 21.2 & 37.2 & 19.4 & 38.3 & 42.3 & 22.5 & 56.8 & 20.7 & 8.9 & 29.4 & 61.7 \\
\hline
\end{tabular}

\subsection{Self-assessment of sustainability knowledge}

Test-takers assessed their performance on the SLT (Table 4). Most students (79\%) rated their sustainability knowledge between very poor and average. Only a fraction of the students $(21 \%)$ considered their sustainability literacy as either good or very good. The self-assessment scores of the educators showed that most of them (61\%) gauged their sustainability knowledge as between very poor and average. Interestingly, over a third (39\%) of the educators assessed their sustainability literacy as either good or very good. The self-assessment conducted by the practitioners showed that more than half $(58 \%)$ of them perceived themselves as possessing an average sustainability knowledge. A fairly sizable proportion (30\%) felt that they had a good 
sustainability literacy, whilst a negligible number (1\%) rated their knowledge as very good. There were no statistically significant differences based on discipline, institution, employment, academic qualification and length of experience $(p \leq 0.001)$. Thus, a sizeable proportion of the educators considered themselves sufficiently knowledgeable about sustainability.

Table 4. Stakeholder self-assessment of sustainability knowledge

\begin{tabular}{|c|c|c|c|}
\hline \multicolumn{2}{|l|}{$\begin{array}{l}\text { Survey prompt: Based on your response to } \\
\text { SLT questions, how would you rate your } \\
\text { sustainability knowledge? }\end{array}$} & Frequency & Percent \\
\hline \multicolumn{4}{|l|}{ Students $(n=232)$} \\
\hline & Very poor & 9 & 3.9 \\
\hline & Poor & 54 & 23.5 \\
\hline & Average & 118 & 51.3 \\
\hline & Good & 44 & 19.1 \\
\hline & Very good & 5 & 2.2 \\
\hline & Total & 230 & 100.0 \\
\hline \multicolumn{4}{|l|}{ Educators $(n=84)$} \\
\hline & Very poor & 3 & 3.6 \\
\hline & Poor & 20 & 24.1 \\
\hline & Average & 28 & 33.7 \\
\hline & Good & 25 & 30.1 \\
\hline & Very good & 7 & 8.4 \\
\hline & Total & 83 & 100.0 \\
\hline \multicolumn{4}{|l|}{ Practitioners $(n=126)$} \\
\hline & Very poor & 2 & 1.7 \\
\hline & Poor & 9 & 7.7 \\
\hline & Average & 68 & 58.1 \\
\hline & Good & 36 & 30.8 \\
\hline & Very good & 2 & 1.7 \\
\hline & Total & 117 & 100.0 \\
\hline
\end{tabular}

\subsection{Result synthesis}

Combining results of the three clusters within the Nigerian engineering community fostered a holistic insight into the sustainability literacy of the community (Table 5). For the level of UNDESD awareness, the results showed the Nigerian engineering community as generally unaware of the UN Decade. On average, just over a quarter $(29 \%)$ of the engineering community was cognisant of the Decade with a significant majority $(71 \%)$ admitting ignorance. However, the difference in the level of awareness amongst the three categories was observed to be statistically significant $(p \leq 0.001)$. Educators $(33 \%)$ and practitioners $(36 \%)$ indicated a higher level of UNDESD awareness than did students (19\%). Hence, students seemed most uninformed about the Decade.

Table 5. Assessment summary for Nigerian engineering community

\begin{tabular}{|c|c|c|c|c|c|c|c|}
\hline \multirow{2}{*}{$\begin{array}{c}\text { Engineering } \\
\text { Community }(n=442 ; p \\
\leq 0.001)\end{array}$} & \multicolumn{2}{|c|}{$\begin{array}{l}\text { \% UNDESD } \\
\text { Awareness }\end{array}$} & \multicolumn{3}{|c|}{$\%$ SLT Score } & \multicolumn{2}{|c|}{$\begin{array}{c}\text { \% SK Self- } \\
\text { Assessment }\end{array}$} \\
\hline & Yes & No & Correct & Incorrect & $\begin{array}{l}\text { Do not } \\
\text { know }\end{array}$ & High $^{*}$ & Low** \\
\hline Students $(\mathrm{n}=232)$ & 19 & 81 & 19 & 32 & 49 & 21 & 79 \\
\hline Educators $(n=84)$ & 33 & 67 & 21 & 33 & 46 & 39 & 61 \\
\hline Practitioners $(n=126)$ & 36 & 64 & 25 & 40 & 35 & 33 & 67 \\
\hline Average & 29 & 71 & 22 & 35 & 43 & 31 & 69 \\
\hline
\end{tabular}

$*$ High $=$ very good or good $* *$ Low $=$ very poor - average 
The overall performance of the Nigerian engineering community on the sustainability literacy test was poor. Scores revealed a nearly eighty percent incorrect and 'do not know' responses, with just over a fifth (22\%) of the community answering the questions correctly. No significant differences were observed in the performance across the group, although practitioners performed slightly better than educators and students. Sustainability test performance by topics (Table 3) revealed statistically significant differences within the engineering community ( $p \leq$ $0.001)$. Generally, the community demonstrated strength in economic themes with over twofifths of them (42\%) answering the relevant questions correctly. The least known topics were the crosscutting issues whose questions were answered correctly by only a small minority of the community $(8.9 \%)$. Performance of the engineering community on the social and environmental themes was quite low having recorded some significant amount of wrong answers (38.3\% and 56.8\% respectively) as well as 'do not know' responses (42.3\% and $20.7 \%$ respectively). Nonetheless, across the three groups, practitioners excelled in economic and social issues, whilst educators performed best on environmental topics. Students performed better than educators on the crosscutting sustainability themes.

Results of the sustainability knowledge self-assessment revealed that the Nigerian engineering community mostly rated their sustainability knowledge low. Only 3 in 10 people (31\%) had a high opinion of their sustainability knowledge. Comparing the outcome of the self-assessment of sustainability knowledge with actual performance on the test was quite revealing (Table 6). Perception of sustainability knowledge differed markedly from actual scores. For instance, some $21 \%$ of the students thought themselves as possessing either good or very good sustainability knowledge, but only 5\% of them passed the test. Similarly, of the over one-third $(39 \%)$ of the educators who claimed to have either good or very good sustainability literacy, only a fraction (10\%) passed the test. Equally, only a small minority (9\%) of the one-third practitioners $(33 \%)$ with high estimation (good or very good) of their sustainability knowledge performed well on the test. On the whole, even though a proportion of the engineering community $(31 \%)$, on average, rated their sustainability knowledge high, quite an insignificant number of them (8\%) passed the test. However, it is noteworthy that fewer students admitted having adequate sustainability knowledge compared with educators and practitioners.

Table 6. Comparing self-assessment with actual test scores

\begin{tabular}{lcc}
\hline \multicolumn{1}{c}{$\begin{array}{c}\text { Engineering } \\
\text { Community }(\mathrm{n}=442 ; \\
p \leq 0.001)\end{array}$} & $\begin{array}{c}\text { Self-Assessment } \\
\text { \% of good } \text { or very } \text { good claim }\end{array}$ & \% of actual pass on test \\
\hline Students & 21 & 5 \\
\hline Educators & 39 & 10 \\
\hline Practitioners & 33 & 9 \\
\hline \multicolumn{1}{r}{ Average } & $\mathbf{3 1}$ & $\mathbf{8}$ \\
\hline
\end{tabular}

\section{Discussion}

The three criteria used to gauge the sustainability literacy of the Nigerian engineering community are level of UNDESD awareness, score on SLT, and self-assessment of sustainability knowledge.

\subsection{Level of UNDESD awareness}

The survey results show that the Nigerian engineering community is largely oblivious of the Decade. This finding is congruent with reports of poor awareness of several UN initiatives 
including MESA and UNDESD in most African countries (UNEP-MESA 2009; Manteaw 2012). The efficacy of the UNDESD in galvanising global support for sustainability education is therefore of concern; an observation also raised in the UNDESD Final Report (UNESCO, 2014).

Lack of UNDESD awareness is more widespread amongst students than amongst educators and practitioners. Although no explicit cause of this discrepancy can be readily ascertained, the educators conversant with the Decade may not have been informed by concerted sustainability education efforts; otherwise such awareness would have reflected on the students. Additionally, the almost equal level of UNDESD awareness between educators and practitioners suggests information sources other than HEIs, such as international conferences and global political debates platforms. Educators and practitioners have access to these fora which may typically elude the students. Consequently, sustainability literacy could be enhanced by increased participation in international conferences and access to global political issues.

\subsection{Score on sustainability literacy test}

Sustainability literacy test provides a means of expressing the sustainability knowledge of an individual or community. The test is a recurring instrument for gauging sustainability literacy in sustainability education research (Zwickle et al., 2014). Although there are no universally fixed questions on a sustainability quiz, the test is usually framed around sustainability themes and typically contextualised (Kieu, Fernandez and Shaw, 2016). The Nigerian engineering community performed poorly on the sustainability literacy test. The results of the test show no significant differences in the performance based on category, although practitioners performed, albeit negligibly, better than educators and students respectively. Nonetheless, across the sustainability topics, a notable disparity exists in the performance of the community. Practitioners evince relative strength in economic and social topics, whilst educators and students are strong in environmental and crosscutting themes respectively. Variation in topic familiarity is also noted with economic themes being the most familiar topics followed by social, environmental and crosscutting topics. The least known topics across the board are cross-cutting issues; hence the need to emphasise them in an intervention.

Practical experience could account for the excelling of practitioners on the economic and social issues. In the course of executing various engineering works, practitioners typically deal with economic and sometimes social costs of a project. Such exposure to project development issues in real-world settings might explain the relatively good performance of the practitioners on the economic and social questions. Contrastingly, the reason for the difference in the performances of educators and students on the environmental and crosscutting questions is unclear. Perhaps educators are more cognisant of environmental concerns from interactions with their nonengineering environmental colleagues or from access to local environmental politics. Nevertheless, educators' skewed familiarity with environmental topics could not have resulted from any sustainability education efforts considering students' relatively poor performance on the theme. In the same vein, the outperformance of the students on the crosscutting questions may have been due to guesswork. Students' tendencies to ignore the 'don 't know' option on a true/false/don't know question format increases their chances of guessing some answers right. For the crosscutting questions, fewer students ticked the 'don't know' option, which suggests that their relatively higher score on the theme could be mere serendipity. 


\subsection{Self-assessment of sustainability knowledge}

Self-assessment of sustainability knowledge enabled Nigerian engineering community to reflect on their sustainability knowledge with a view to offering an evaluation. Using the sustainability literacy test as a criterion, the self-assessment tool provided an opportunity to check test scores against perceived knowledge. Difference between perceived knowledge and actual knowledge is a recognised phenomenon in cognitive research (Brinol \& Petty 2012). Three theories for bias of knowledge self-assessment are self-esteem, frame of reference and personal relevance of the topic. With the exception of personal relevance which is positively correlated to actual knowledge, self-esteem and reference group have positive and negative correlations to actual knowledge (Radecki and Jaccard, 1995). A high self-esteem is likely to result in an overestimation of knowledge and vice versa. However, low self-esteem at times yields unwarranted knowledge claims in a process called defensive self-esteem mechanism. Reference affects perceived knowledge by contrast or assimilation. When individuals contrast their knowledge within a reference group, a claim to more knowledge is likely if the peer being compared to is deemed less informed; the converse is also true. Assimilation arises when people assert knowledge level of their peers. The personal relevance theory assumes that personal importance of a topic heightens perceived knowledge.

In the case of Nigerian engineering community, self-rating of sustainability knowledge is averagely low. However, educators and practitioners claim greater knowledge of sustainability than students. This difference in sustainability knowledge perception can be explained by either the self-esteem or frame of reference theories. Explanation from personal relevance of the topic is ruled out as results show no significant relationship between sustainability import and perceived sustainability knowledge $(p \leq 0.05)$. Although the self-esteem of Nigerian engineering community was not directly measured, it may explain the self-assurance manifest in educators' self-assessment of sustainability knowledge. Educators have a general tendency to exhibit high self-esteem (Mustaq et al., 2012; Terra, Marziale and Robazzi, 2013) based on several factors including academic qualification. Since the minimum requirement for a lecturing position in Nigeria is a master's degree (BMAS, 2014), engineering educators might have been constrained to claim sustainability knowledge in justification of their educational status. With regards to practitioners' high estimation of perceived sustainability knowledge, the frame of reference theory could be at work. Lending credence to this assertion is the fact that participants for practitioner category in the study were recruited mainly from professional associations and groups. Engineering professionals filling out a survey in the same room is an archetypal setting for assimilation effect, and may have influenced the sustainability selfassessment of the practitioner cohort.

\subsection{Some unexpected findings}

\subsubsection{Low familiarity with environmental topics}

An unexpected outcome of the study is the low score on environmental questions featured in the sustainability literacy test. Studies have often reported environment as the most dominant sustainability theme in engineering education (Hanning et al., 2012; Watson et al., 2013; UNESCO, 2014). Furthermore, the fairly long-standing tradition of teaching environmental topics in Nigeria equally increased optimism in a positive outcome for the environmental themes. Thus, the lack of familiarity with contextual environmental issues shown by the Nigerian engineering community is unanticipated. However, it is possible that environmental education has been restricted to only environmental engineering students and not covered in the common courses. In this case, non-environmental students will not benefit from lessons on 
the environment. This might also explain the poor performance of the majority amongst educators and practitioners, being products of the same education system. This finding has important implication for sustainability literacy as it suggests the possibility of environmental issues not being adequately addressed by Nigerian engineers in the field. Hence, sustainability education intervention for Nigeria should not take environmental learning as a given in the engineering curriculum.

\subsubsection{Fewer students admit adequate sustainability knowledge}

Fewer students than expected claimed ample knowledge of sustainability. This contrasts with findings of many studies which show that students, more often than not, overestimate their actual knowledge (Lundeberg et al., 2000; Yadav et al., 2011). Consequently, having about 8 in 10 students (81\%) admitting inadequate sustainability knowledge is remarkable, but also reassuring. Students might have been persuaded to be more open about their sustainability knowledge by the apparent research objective of introducing sustainability into Nigerian engineering education. This information might have encouraged them to genuinely admit ignorance of sustainability in the hope of benefiting from an introductory course on engineering sustainability. This fact is important as it implies that students are willing to learn about sustainability. Consequently, a sustainability education intervention for Nigerian engineering curriculum could draw strength from such potential.

\subsection{Comparison between the sustainability literacy levels of the Nigerian engineering students and The Ohio State University students}

In the study by Zwickle et al (2014) which presented the sustainability literacy test scores of a student population at The Ohio State University, there was a total average score of $69 \%$. The assessment scores for the economic, environmental and social domains were $71 \%, 73 \%$ and $61 \%$ respectively. There were significant differences in the performances of freshmen, sophomores and juniors. Of the three student groups, the freshmen were the least sustainability literate. It is noteworthy that a few of the questions posed to The Ohio State University students were equally featured on the sustainability test administered to the Nigerian engineering community. Precisely, Q1 - Ozone layer protects us from acid rain and temperature fluctuations and Q8 - Long-term profitability is the most commonly used definition of economic sustainability appeared on both tests. Consequently, comparing the results from the two data sets may provide some interesting insights.

In terms of overall sustainability literacy, the Nigerian engineering students, having recorded a mean score of $20 \%$, appear less knowledgeable than the students from The Ohio State University, whose average score was 69\%. Equally, twice as many Nigerian engineering students as The Ohio State University students provided the correct answers to the economic questions. Similarly, the percentage of the Nigerian students who answered the environmental questions correctly was one-third of the percentage of The Ohio State University students who did likewise. Furthermore, more Ohio State University students responded correctly to the social questions than the Nigerian engineering students. Since the crosscutting questions were not posed to the Ohio students, there is no basis for comparison with the Nigerian students. However, an interesting observation is made regarding the two questions (Q1 and Q8) which featured on both of the sustainability literacy tests. Whilst merely $10 \%$ of the Nigerian students answered Q1 correctly, an overwhelming $92.1 \%$ of the Ohio students provided the correct answer to the question. For Q8, more than half $(51.7 \%)$ of the Nigerian students responded correctly, which is in contrast to the less than half $(46.3 \%)$ of the Ohio students that answered the question correctly. 
To make sense of these facts, it is instructive to note that the sample composition of The Ohio State University comprises both engineering and non-engineering students. The Nigerian sample consists strictly of engineering students. Although the sample sizes differ (Nigeria: $\mathrm{n}=232$; Ohio: $\mathrm{n}=1,389$ ), this may not be significant given the conventional sample size minimum requirement of $n=100$ for a $95 \%$ confidence level. In any event, the comparison between the two data sets demonstrates that there is, on average, a higher sustainability literacy amongst the students from The Ohio State University than amongst the Nigerian students. The involvement of non-engineering students from the Ohio State University may have influenced the outcome of the test. Social science students are likely to be more exposed to sustainability issues than engineering students. However, not all the sustainability concepts are familiar to the students of the US-based institution. Obviously, the Nigerian engineering students are more aware of some sustainability basics than The Ohio State University students as evidenced by their performance on Q8. Hence, sustainability education intervention should not proceed with the assumption that the students in the developed world are necessarily more sustainability literate than their counterparts in the rest of the world. The implication for Nigeria is that any means of intervention must be context-based.

\section{Limitations}

Some limitations are acknowledged in the study. One of these challenges involves the quantification of sustainability literacy based on level of UNDESD awareness. This cognisance gauge assumes that the 10-year global plan of educating the world for sustainability somehow influences sustainability literacy. Such association between sustainability literacy and level of UNDESD awareness may not be necessarily accurate. Often, people benefit from policy outcomes with whose guiding framework they are not conversant. Thus, it is conceivable for the engineering community in Nigeria to be sustainability literate without being aware of UNDESD. However, the chances of such occurrence in the community are quite slim as the results eventually showed: level of UNDESD awareness did not differ significantly from scores on the sustainability literacy test. Hence, UNDESD awareness is an appropriate contributor to sustainability literacy, and thus an important variable in the present study.

Another challenge of the study is limitation due to the constraints inherent in the designed sustainability literacy test. As already highlighted in Section 2.2, the design of the sustainability literacy test was constrained by time and testable content. To achieve a balance between these factors, the 'true/false/don't know' question format was adopted featuring some sixteen questions across four sustainability themes. This questioning style is prone to guesswork, but useful for addressing a wide-range of issues and for examining conceptual knowledge (Building, 2017). Although the inclusion of 'don't know' option had been intended to forestall conjecture, it is not a perfect countermeasure. Respondents can ignore the option and alternate arbitrarily between the true and false choices. However, such question-answering pattern was not observed in the data in any significant proportions. Additionally, focus on sustainability basics corresponds with the strength of the test format in aiding assessment of conceptual knowledge and consequently suitable for the study. Nonetheless, for examining deeper sustainability knowledge the online international sustainability literacy test (SLT, 2016) could be employed.

\section{Conclusions}

The sustainability literacy of the Nigerian engineering community was assessed based on three criteria: level of UNDESD awareness; performance on SLT; and self-assessment of sustainability knowledge, and across three groups: students; educators; and practitioners. The 
resulting categorical data were analysed and subsequently synthesised to holistically gauge the literacy level of the engineering community. From these analyses a number of findings ensued as presented and discussed in this paper. Firstly, the Nigerian engineering community was found to generally exhibit a low sustainability literacy, with a significant majority performing unsatisfactorily on all the assessment criteria. Secondly, there was an evidence of widespread ignorance of the UNDESD within the Nigerian engineering community with students being the most uniformed. Thirdly, Nigerian engineering community were more familiar with economic topics as more than two-fifths of them answered correctly the economic questions featured on the SLT. Fourthly, the least known sustainability themes across the board were the crosscutting issues. Finally, some unexpected findings of the study were little familiarity with environmental themes and sincerity of the students in admitting sustainability illiteracy.

Overall, the findings highlighted in this paper indicate the need to improve the sustainability literacy of the Nigerian engineering community, possibly through a sustainability education intervention. Based on the finding of a low sustainability awareness, especially amongst the engineering students, a course entitled "An Introduction to Sustainable Engineering in Nigeria" could be devised for the Nigerian engineering curriculum. The course should contain the wideranging issues highlighted in the present study including contextual sustainability matters and the universality of the sustainability challenge. This would help address the gap discovered in the Nigerian engineering community's awareness of the various sustainability dimensions. Being an introductory course, the module should establish the imperative, raison d'etre, and the rationale for sustainable engineering as well as the application and relevance of engineering sustainability in Nigeria. Examples of topics that could feature in the course are the Origins of Sustainable Engineering, Systems Thinking, and The Engineer as a Leader. Others are Sustainable Engineering in Nigeria, Application of Sustainable Engineering and Earth Systems Engineering and Management. Considering the packed nature of the engineering curriculum, the course could fit into the common/elective courses of the Nigerian engineering curriculum. It could aptly subsume and replace the ubiquitous Engineer in Society course currently taught in all engineering institutions in Nigeria.

\section{References}

AAU (2009) Abuja Declaration on Sustaianble Development in Africa: The Role of Higher Education, 12th General Conference of Association of African Universities. doi: 10.1089/SUS.2009.9822.

Akeel, U., Bell, S. and Mitchell, J. (2017) 'Engineering and sustainability education in Nigeria', in Proceedings of the 45th SEFI Annual Conference 2017 - Education Excellence for Sustainability, SEFI 2017.

Allenby, B. (2007) 'Sustainable Engineering Education: Translating Myth to Mechanism', Environmental Quality Management, 17(1), pp. 17-26. doi: 10.1002/tqem.20148.

Azapagic, A., Perdan, S. and Shallcross, D. (2005) 'How much do engineering students know about sustainable development? The findings of an international survey and possible implications for the engineering curriculum', European Journal of Engineering Education, 30(1), pp. 1-19.

BMAS (2014) 'Benchmark minimum academic standards and accreditation scoring criteria for undergraduate engineering programmes in Nigerian universities'. Abuja, Nigeria: Council for the Regulation of Engineering in Nigeria, p. 376.

Brinol, P. and Petty, R. E. (2012) 'Knowing Our Attitudes', in Vazier, Si. and Wilson, T. D. 
(eds) Handbook of Self-Knowledge. New York: The Guilford Press, p. 462.

Building, T. O. (2017) 'Guide to Assessment', Scottish Qualifications Authority.

Carteron, J.-C. and Decamps, A. (2017) Mapping awareness of the global goals. New York.

Etse, D. and Ingley, C. (2016) 'Higher education curriculum for sustainability: course contents analyses of purchasing and management programme of polytechnics in Ghana', International Journal of Sustainability in Higher Education, 17(2), pp. 269-280. doi: 10.1108/14676371311312905.

Falola, T. and Heaton, M. M. (2008) A History of Nigeria. Cambridge University Press. doi: 10.1017/CBO9780511819711.

Hanning, A., Priem, A. A., Lundqvist, U. and Svanström, M. (2012) 'Are we educating engineers for sustainability?: Comparison between obtained competences and Swedish industry's needs', International Journal of Sustainability in Higher Education, 13(3), pp. 305320 .

Kieu, T. K., Fernandez, G. and Shaw, R. (2016) 'Usefulness of a Sustainability Literacy Test', Sustainable Development and Disaster Risk Reduction, Springer J, pp. 265-277.

Lundeberg, M. A., Fox, P. W., Brown, A. C. and Elbedour, S. (2000) 'Cultural Influences on Confidence: Country and Gender.', Journal of Educational Psychology, 92(1), pp. 152-159. doi: 10.1037/0022-0663.92.1.152.

Manteaw, O. O. (2012) 'Education for sustainable development in Africa: The search for pedagogical logic', International Journal of Educational Development, 32(3), pp. 376-383. doi: 10.1016/j.ijedudev.2011.08.005.

Mustaq, N., Shakoor, A., Azeem, M. and Zia, N. (2012) 'Self-esteem's difference among primary, elementary, secondary and higher secondary schools teachers university of education', International Journal of Humanities and Social Science, 2(1), pp. 200-205.

Ojiako, G. . (1986) 'University Engineering Education and Training in Nigeria: Development, Weaknesses and Improvements', Nijotech, 10(1), pp. 46-56.

Radecki, C. M. and Jaccard, J. (1995) 'Perceptions of knowledge, actual knowledge, and information search behaviour', Journal of Experimental Social Psychology, 31, pp. 107-138.

Sara Parkin, Johnston, A., Buckland, H., Brookes, F. and White, E. (2004) 'Learning and Skills for Sustainable Development: Developing a sustainability literate society. Guidance for Higher Education Institutions'. Forum for the Future.

SLT (2016) Sultitest. Available at: https://www.sulitest.org/en/index.html.

Stibbe, A. (2010) The Handbook of Sustainability Literacy: Skills for a changing world. First. Edited by A. Stibbe. Devon: Green Books Ltd.

Terra, F. de S., Marziale, M. H. P. and Robazzi, M. L. do C. C. (2013) 'Evaluation of selfesteem in nursing teachers at public and private universities', Revista Latino-Americana de Enfermagem, 21 Spec No, pp. 71-78.

Thakran, S. (2004) 'Education for Sustainable Development Innovations':, Educational Quest: An International Journal of Education and Applied Social Sciences, 6(1), pp. 1-13. doi: 10.5958/2230-7311.2015.00009.4.

UNEP-MESA (2009) Supporting Universities to Respond to Environment, Sustainable Development and Climate Change Challenges. 
UNESCO (2014) Shaping the Future We Want. doi: 10.5363/tits.11.4_46.

Vare, P. and Blewitt, J. (2010) 'Sustainability Literacy: Two Perspectives', in Stibbe, A. (ed.) The Handbook of Sustainability Literacy. E-Book. Devon: Green Books Ltd, p. 224.

Watson, M. K., Lozano, R., Noyes, C. and Rodgers, M. (2013) 'Assessing curricula contribution to sustainability more holistically: Experiences from the integration of curricula assessment and students' perceptions at the Georgia Institute of Technology', Journal of Cleaner Production, 61, pp. 106-116.

Yadav, A., Subedi, D., Lundeberg, M. A. and Bunting, C. F. (2011) 'Problem-based Learning: Influence on Students' Learning in an Electrical Engineering Course', Journal of Engineering Education, 100(2), pp. 253-280. doi: 10.1002/j.2168-9830.2011.tb00013.x.

Zwickle, A., Koontz, T., Bodine, A. and Slagle, K. (2013) 'Assessment of Sustainability Knowledge (ASK)'. The Ohio State University and University of Maryland, p. 8.

Zwickle, A., Koontz, T., Slagle, K. and Bruskotter, J. (2014) 'Assessing sustainability knowledge of a student population. Developing a tool to measure knowledge in the environemntal, economic and social domains', International Journal of Sustainability in Higher Education, 15(4), pp. 375-389.

\section{Appendix A: Assessment of Sustainability Literacy}

1. Are you aware of the United Nations Decade of Education for Sustainable
Development?
O Yes
O No

2. Indicate whether the following statements are true or false. Tick the "Do not know" option if you are not sure of the correct answer.

\begin{tabular}{|c|c|c|c|}
\hline Sustainability Literacy Test & $\stackrel{\mathscr{E}}{E}$ & 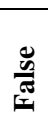 & ค̊ \\
\hline a. Ozone layer protects us from acid rain and temperature fluctuations & $\mathbf{O}$ & $\mathbf{O}$ & $\mathbf{O}$ \\
\hline b. Carbon monoxide is one of the greenhouse gases that cause global warming & $\mathbf{O}$ & $\mathbf{O}$ & $\mathbf{O}$ \\
\hline c. The main focus of the Kyoto Protocol adopted in 1997 was nuclear waste & $\mathbf{O}$ & $\mathbf{O}$ & $\mathbf{O}$ \\
\hline $\begin{array}{l}\text { d. Agenda } 21 \text { is a global treaty signed by UN member nations at the Stockholm Earth } \\
\text { Summit in } 1992\end{array}$ & $\mathbf{O}$ & $\mathbf{O}$ & $\mathbf{O}$ \\
\hline e. Global population stood at 1.6 billion in 1900 & $\mathbf{O}$ & $\mathbf{O}$ & $\mathbf{O}$ \\
\hline \multicolumn{4}{|l|}{ f. Less than 1 million people in the world have no access to clean drinking water } \\
\hline $\begin{array}{l}\text { g. Engineers' role in sustainability suffices with ensuring that their designs or systems do not } \\
\text { harm the environment }\end{array}$ & $\mathbf{O}$ & $\mathbf{O}$ & $\mathbf{O}$ \\
\hline h. Long-term profitability is the most commonly used definition of economic sustainability & $\mathbf{O}$ & $\mathbf{O}$ & $\mathbf{O}$ \\
\hline $\begin{array}{l}\text { i. The review of global poverty line to US } \$ 1.90 \text { was spurred by worldwide sustainability } \\
\text { activisms }\end{array}$ & $\mathbf{O}$ & $\mathbf{O}$ & $\mathbf{O}$ \\
\hline j. Economic development and environmental protection are mutually exclusive & $\mathbf{O}$ & $\mathbf{O}$ & $\mathbf{O}$ \\
\hline $\begin{array}{l}\text { k. The sustainability pillars of environment, society and economy are widely accepted to be } \\
\text { in a hierarchical, rather than equal, relationship }\end{array}$ & $\mathbf{O}$ & $\mathbf{O}$ & $\mathbf{O}$ \\
\hline $\begin{array}{l}\text { I. In the landmark Brundtland Report of } 1987 \text {, the terms sustainability and sustainable } \\
\text { development are used interchangeably }\end{array}$ & $\mathbf{O}$ & $\mathbf{O}$ & $\mathbf{O}$ \\
\hline $\begin{array}{l}\text { m. Nigeria failed to ratify the UN } 2030 \text { Agenda for Sustainable Development in } 2015 \text { as } \\
\text { presidential elections held in the country at the time. }\end{array}$ & $\mathbf{O}$ & $\mathbf{O}$ & $\mathbf{O}$ \\
\hline $\begin{array}{l}\text { n. Federal Environmental Protection Agency is the primary agency that oversees } \\
\text { environmental regulation in Nigeria }\end{array}$ & $\mathbf{O}$ & $\mathbf{O}$ & $\mathbf{O}$ \\
\hline $\begin{array}{l}\text { o. Breeding of animals in zoos is the most significant driver in the loss of species and } \\
\text { ecosystems around the world }\end{array}$ & $\mathbf{O}$ & $\mathbf{O}$ & O \\
\hline
\end{tabular}

3. Based on your response to the above questions, how would you rate your sustainability knowledge? O Very poor O Poor O Average $\mathbf{O}$ Good $\mathbf{O}$ Very good 